\title{
CÉCILE LIGNEREUX, L'éloge, maillon faible de la lettre de remerciement?
}

\section{Laura Rescia}

\section{OpenEdition}

\section{Journals}

\section{Edizione digitale}

URL: http://journals.openedition.org/studifrancesi/16342

DOI: 10.4000/studifrancesi. 16342

ISSN: 2427-5856

\section{Editore}

Rosenberg \& Sellier

\section{Edizione cartacea}

Data di pubblicazione: 1 juillet 2019

Paginazione: 156-157

ISSN: 0039-2944

\section{Notizia bibliografica digitale}

Laura Rescia, «CÉcILE LIGNEREUx, L'éloge, maillon faible de la lettre de remerciement?», Studi Francesi

[Online], 187 (LXIII | I) | 2019, online dal 01 juin 2019, consultato il 24 janvier 2021. URL: http:// journals.openedition.org/studifrancesi/16342 ; DOI: https://doi.org/10.4000/studifrancesi.16342

Questo documento è stato generato automaticamente il 24 janvier 2021.

\section{@(@) $\Theta \Theta \Theta$}

Studi Francesi è distribuita con Licenza Creative Commons Attribuzione - Non commerciale - Non opere derivate 4.0 Internazionale. 
CÉCILE LIGNEREUX, L'éloge, maillon faible de la lettre de remerciement?

Laura Rescia 


\section{NOTIZIA}

CÉCILE LIGNEREUX, L'éloge, maillon faible de la lettre de remerciement?, [En ligne] «Exercices de rhétorique» 11, 2018, mis en ligne le 08 octobre 2018; URL: http://

journals.openedition.org/rhetorique/642

1 La rivista elettronica Exercices de rhétorique, inaugurata nel 2013 e dedicata all'analisi delle pratiche retoriche in tipologie testuali differenti, consacra un numero tematico alla pratica dell'elogio, dall'Antichità alla Contemporaneità.

2 L'articolo di Lignereux esamina come si inserisca l'elogio in seno alla struttura della lettera di ringraziamento, in particolare nei manuali del secondo Seicento francese. Inaspettatamente, l'elogio fatica a trovare collocazione in tale contesto discorsivo: tale diffidenza nei confronti di un dispositivo retorico apparentemente adeguato a un contesto di espressione della gratitudine sembra essere dovuto al carattere intrinseco che tale tipologia epistolare riveste agli occhi del Classicismo. Poiché si tratta, afferma l'A., di persuadere il destinatario della riconoscenza dello scrivente, l'elogio sembra rischioso, in quanto potrebbe diminuire la forza persuasiva della lettera se venisse interpretato come ambiguo o ipocrita. I modelli della lettera di ringraziamento dunque sembrano espungere l'elogio dalla sequenza protocollare, articolata in tre fasi (esprimere contentezza, esagerare il beneficio ottenuto, prometterne memoria e riconoscenza eterne), salvo riassorbirlo nella seconda fase dell'argomentazione, quando dalla lode per il beneficio si scivola verso quella del benefattore. L'analisi di questo dispositivo retorico e del suo utilizzo nei manuali epistolari dimostra che questi ultimi non sono semplici raccolte fraseologiche, ma lasciano spazio a una riflessione tipicamente retorica sulle condizioni del loro utilizzo. 